\title{
ORIGENS DA LIMITAÇĀO LEGAL DA JORNADA DE TRABALHO
}

JOSÉ ANTONIO PERES GEDIEL

SUMĀRIO: I - Introdução: Fundamentos Meta-Jurídicos da Limitação da Jornada de Trabalho. II - Surgimento e Evolução das Normas Regulamentadoras da Jornada de Trabalho. III - A Contribuição do Direito Internacional do Trabalho.

\section{I - INTRODUÇÃO - FUNDAMENTOS META-JURIDICOS DA LIMITAC̣ĀO DA JORNADA DE TRABALHO}

A presente reflexão sobre a origem das normas nacionais, estrangeiras e internacionais, que regulam ou que tenham regulado a duração do trabalho, restringir-se-á a examinar as condições sociais em que as mesmas surgiram e foram ou não aplicadas, a partir do final do século XVIII, até nossos dias. Trata-se, portanto, de breve estudo histórico a respeito das regras limitadoras da duração do chamado "trabalho livre", conhecido na Europa Ocidental, após a segunda metade do século XVIII, com a desagregação do regime feudal e a tomada do aparelho pol ítico-estatal pela burguesia.

A limitação do trabalho humano, tanto no período a ser estudado, quanto em épocas anteriores, apresentou-se como uma necessidade fundamentada em vários fatores. O primeiro deles é a própria natureza biológica e psicológica do homem, cuja capacidade de atividade não é ilimitada e tende a diminuir e a se exaurir, quando exercida por longos espaços de tempo, sem que hajam interrupções para a reposição das. energias gastas.

"A fadiga suscita no trabalhador uma sensação particular de si mesmo que the indica a importância do esforço que realiza e os limites que é mister que lhe imponha. Atua, pois, como um regulador de atividades, e não existe esforço algum, ainda que se realize sem nenhuma obrigação ou se revista da forma de um jogo, que não provoque fadiga. Esta é, no princípio, fisiológica e "sã", mas se o indiv íduo não lhe pres- 
ta atenção e continua trabalhando, se torna crônica, isto é, desaparece mais dificilmente com o descanso, se acumula à medida em que transcorrem os dias e desemboca nos estados francamente patológicos do "distress" e, inclusive, no esgotamento orgânico (como o que em uma ocasião provocou a morte de um ciclista participante da volta da França), psíquico (neurose) ou psicossomático (úlceras estomacais, enfarte do miocárdio, etc. . . $)^{\prime \prime}{ }^{1}$

Outro fator que determina a limitação do trabalho humano é a forma pela qual o homem se organiza socialmente. A vida em sociedade exige a participação dos indivíduos não apenas nas atividades produtivas economicamente, mas também em outras atividades de caráter lúdico, religioso, sexual, artístico, etc. . . Os fatores sócio-econômicos também influem na limitação da duração do trabalho e se esboçam em todos os tipos de sociedades conhecidas, a partir da divisão do trabalho, com base em diferentes critérios, tais como idade, sexo, raça, casta, classe social, etc. . .

Assim, podemos extrair do livro de Roland Cuvillier o seguinte trecho ilustrativo: "Na Áustria, o Conselho de Questões Econômicas e Sociais estimou que, de 1959 a 1975, a redução da duração do trabalho - tendo em conta os aumentos de produtividade induzidos - determinou um aumento de 60 por cento do emprego (prescindindo dos ciclos conjunturais); entre ambos os anos, a semana laboral diminuiu de $48 / 45$ horas a 40 e as férias anuais pagas passaram a ser de três semanas, e logo quatro. Na França, a diminuição de trinta minutos por ano da semana laboral média entre 1967 e 1976 teria permitido a criação de 50.000 empregos anuais, apesar dos aumentos de produtividade e sem ter em conta os efeitos do crescimento. Segundo outra estimativa, a criação de empregos somente proviria, há dez anos, da redução média do trabalho, já que a produtividade e a produção aumentaram muito lentamente neste país desde $1937^{\prime \prime}{ }^{2}$

De qualquer modo, tais questões precisam ser tratadas globalmente (para que sejam contornados, outros problemas que da solução de certas questões poderiam advir e é necessário também que, apesar da tendência para a limitação da jornada e para considerar os benefícios que desta redução poderiam decorrer, se tenha consciência de que isto se insere em um todo e de que tal problema se relaciona a outros. Dest'arte, há necessidade de uma série de medidas diversas da simples limitação de horas de trabalho, quais sejam a melhora nas condições e no ambiente de trabalho, a criação de medidas capazes de despertar no empregado um maior gosto e interesse pelo tipo de trabalho que realiza, entre outras coisas.

O tratamento global do problema é o que propõe Rolande Cuvillier, na seguinte passagem de sua obra:

1. CARPENTIER, J e CAZAMIAN, P. - "El Trabajo Nocturno", Genebra, 1977, publicação da O. I. T., pág. 22.

2. CUVILLIER, Rolande - "Hacia la reducción de la duración del trabajo?", Genebra, O.I.T., 1982, página 126. 
"Do presente estudo se extrai de modo constante a necessidade de não prever a redução da duração do trabalho, como uma medida isolada, aplicável sem matizes, do exterior. As reduções que se inscrevem no marco da prossecução da baixa tendencial do tempo de trabalho satisfazem esta condição e por isto se considera, comumente, que não trazem nenhum problema. Em troca, se se quizesse acelerar essa diminuição poderiam surgir riscos no aspecto econômico, em matéria de inflação e de balanço de pagamentos, particularmente, com a possibilidade não apenas de não reduzir o desempenho, mas sim até de agravá-lo. De todo modo, raciocinar assim equivale a supor que a situação é estática com respeito às políticas seguidas em matéria econômica de emprego. Mudar tais políticas poderia modificar os prognósticos pessimistas que acabam de ser mencionados". ${ }^{3}$

Parece geralmente aceito que as repercussões de eventuais reduções da duração do trabalho dependeriam da política de redução que se aplicassem, das medidas de apoio e de acompanhamento de que gozassem e do contexto político, econômico e social do conjunto no qual se inscrevessem.

Entende, ainda, a autora que perspectivas deveriam ser abertas em várias esferas, entre estas política econômica, política de emprego e do aproveitamento dos recursos humanos, transferências e redistribuição das receitas, utilização do tempo livre.

Conclui, dizendo: "A reflexão atual sobre a redução da duração do trabalho, tanto se expressa em informes oficiais, como nas posturas dos interlocutores sociais, orienta-se para enfoques flexíveis e progressivos que têm em conta ao máximo os imperativos econômicos e as preferências individuais em matéria de trabalho, de ócios e de receitas. Estes enfoques exigem um esforço de imaginação e, com freqüência, de inovação". ${ }^{4}$

\section{II - SURGIMENTO E EVOLUÇĀO DAS NORMAS REGULAMENTADORAS DA JORŃNADA DE TRABALHO}

\section{NA EUROPA}

Apesar dos fundamentos acima apontados, do final do século XVIII, até a segunda metade do século XIX, a burguesia da maior parte dos países Europeus, tendo controlado o processo produtivo e se assenhorado do poder político do Estado, impôs à classe trabalhadora européia condições de trabalho que não levavam em conta nem mesmo a limitação física do organismo dos trabalhadores, uma vez que se buscava, tão somente, o maior lucro, a maior acumulação de riquezas, de modo a permitir a expansão do capital burguês.

A respeito desse momento histórico, é forçoso que se diga que o

3. CUVILLIER, Rolande - obra citada.

4. Idem, ibidem. 
importante movimento de reformas pol íticas e sociais que se esboçavam nessa época, na França, na Inglaterra, na Alemanha e outros pa íses, visava não só romper os privilégios da aristocracia e do clero, mas, sobretudo, adequar a máquina do Estado aos interesses da burguesia.

As filosofias liberais, ao mesmo tempo que combatiam o absolutismo, afirmavam os direitos naturais dos homens, dessacralizavam a autoridade dos governantes, colocavam em pé de igualdade, formal, ideal, a-histórica, o taifeiro e o "grand-bougeois", beneficiando, neste ponto, os patrões, que contratavam "livremente" com os trabalhadores, seguindo apenas as leis naturais do mercado (a da oferta e da procura, por exemplo), sem que as autoridades estatais se preocupassem em regular juridicamente tais situações de desigualdade econômica real.

Para desorganizar, definitivamente, as antigas relações de produção e evitar as pressões dos trabalhadores, o Estado Burguês negava a esses "novos homens livres" o direito de livre associação, em nome do princípio da liberdade do trabalho, consubstanciado, por exemplo, no artigo 7 da lei de 1791, conhecida sob o nome da "Lei d'Allarde", votada pela Assembléia Constituinte Francesa.

Assim, os desdobramentos da filosofia e da retórica liberais vinham, quase sempre, favorecer os patrões e prejudicar os trabalhadores que, muitas vezes, eram tratados desigualmente pelo próprio tex to legal. André Brun e Henri Galland observam que o artigo 1781 do Código Civil Francês (revogado em 1868), "créa un privilége exorbitant en faveur des patrons: ceux-ci étaint crus "sur' leurs affirmations", pour tout ce qui touche au paiement et à la quotite des salaires. Ancune place n'était faite à la lesion dont pourraient être victimes les salariés dans le contrat de louage "de services, allors que celles-ci était retenue au profit des vendeurs d'immeubles. II y a mieux encore: si, d'aventure, le legislateur sorsortait de son attitude d'indifférence, c'était pour manifester des séntiments de défiance à l'égard des salariés" ${ }^{\prime 5}$

Economicamente mais fracos, sem nenhuma proteção jurídica, sem qualquer participação política e socialmente desagregados, os trabalhadores da nascente era industrial viam, ainda, seus empregos serem tomados pelas máquinas, que desequilibravam o mercado de trabalho. Foi nesse contexto de desemprego, de jornadas de trabalho de até 16 horas e salários aviltantes, que surgiram as primeiras reações operárias de forma expontânea e quase irracional, como a revolta dos trabalhadores da "Black England", que se uniram para destruir as máquinas das indústrias de lã, para reivindicar melhores condições de trabalho.

Passados esses primeiros momentos, organizaram-se as associações, as sociedades operárias de socorro mútuo, que congregavam os trabalhadores das grandes fábricas e que, apesar da violência com que foram reprimidas, passaram a reivindicar em conjunto, aos patrões, melhores condições de trabalho, principalmente, menores jornadas para as crian-

5. BRUN, André et GALLAND, Henri - Droit du Travail, Tome 1, 2a. Edition, Sirey, Paris, 1978, página 11. 
ças e mulheres. Arnaldo Sussekind, registra: “A primeira manifestação conhecida por parte das trade-unions, data de 1720, quando uma associação de alfaiates pleiteou ao Parlamento inglês melhores salários e menor jornada de trabalho. Quando, em 1799 e 1800 os Combinations Acts proibiam as coalizações de operários e de patrões, inúmeras eram as associações de trabalhadores que marcaram o in ício do sindicalismo. Nessa época, algumas desapareceram, outras se transformaram em associações de socorro mútuo ou conservaram a sua característica, como associações de resistência". 6

A partir daí, a luta pela obtenção de melhores condições de trabalho e sua regulamentação legal pelo Estado, em quase todos os países europeus em que ocorreu a "revolução industrial", passou pela via do sindicalismo, cuja importância pode ser plenamente avaliada pelo contido na afirmação: "in the most higly industrialized country the fight for political and economic emancipation of the urban working classes passed into non-revolutionary channels". ${ }^{7}$

Assim, pouco a pouco, os trabalhadores obtiveram vitórias, conseguindo a elaboração de uma legislação trabalhista que, no tocante à duração do trabalho vai sendo contruída, paralelamente, em vários países industrializados, podendo seu desenvolvimento ser acompanhado, de forma não exaustiva, a partir de 1802, quando na Inglaterra foi proibido o trabalho de crianças à noite, ou por mais de doze horas.

$\mathrm{Na}$ França, onde a industrialização foi mais lenta e o aparelho estatal mais repressivo, somente em 1841 a jornada de trabalho das crianças de oito a doze anos ficou limitada a oito horas diárias e para os menores, com idade de doze a dezesseis anos, a jornada de trabalho ficou sendo de, no máximo, doze horas.

No avanço das lutas pela obtenção de uma legislação trabalhista, deve se destacar a atuação da União Nacional Consolidada que, na Inglaterra, chegou a reunir meio milhão de filiados, tendo como uma de suas finalidades precípuas a elaboração de uma Carta Constitucional do Trabalho, deflagrando, para tal, o conhecido "Movimento Cartista", que culminou com o estabelecimento da jornada de trabalho de dez horas, em 1847.

$\mathrm{Na}$ França, o estabelecimento de uma jornada de dez horas em Paris e onze nas províncias deu-se durante o período revolucionário de 1848, mas esta e outras vitórias obtidas pelos trabalhadores foram duramente destruídas pela reação anti-social do Império Liberal de Napoleão III: “la répression sévére du Céneral Cavaignac fut suivie de l'anéantissement des reformes sociales" ${ }^{\prime \prime}{ }^{8}$

6.SUSSEKIND, Arnaldo - Direito Internacional do Trabalho, LTR, São Paulo, 1983, página 75.

7.NAMIER, Lewis - 1848: "The Revolution of the Intellectuals", Anchor Books, New York, 1964, página 1.

8. BRUN, André et GALLAND, Henri - obra citada, página 19. 


\section{NOS ESTADOS UNIDOS DA AMÉRICA}

Nos Estados Unidos, único país americano atingido pela "revolução industrial", após a Guerra da Secessão, a burguesia industrial do norte foi pouco a pouco sendo forçada a abandonar as regras de direito consuetudinário herdadas da Inglaterra, referentes à associação dos trabalhadores, e ao findar o século XIX, na região dos Grandes Lagos, pela pressão dos trabalhadores associados, a jornada de trabalho já havia sido reduzida para oito horas.

Gordon F. Bloom e Herbert R. Northrup perguntam se a diminuição de horas de trabalho, que se viabilizou graças a uma série de fatores, ter-se-ia materializado caso não tivesse havido a agitação de grupos operários e liberais, e a legislação de governos estaduais e federais. Defendem estes autores que a acumulação de capital tornou possível a diminuição de horas, mas sustentam que a "maioria dos empregadores diminuiu a jornada de trabalho (ou a semana laboral) somente sob algum tipo de compulsão - do Estado, de seus colegas empregadores ou sindicatos".. .

Uma das primeiras manifestações do movimento pela diminuição de horas de trabalho foi na forma de uma resolução adotada pelos operários carpinteiros da Filadélfia que, em 1871, declaravam que uma jornada laboral deveria durar somente das seis horas da manhã às seis horas da tarde. Mas os hábitos de uma sociedade agrícola acostumada ao labor desde o nascer do sol até o crepúsculo, com a crença de que o tempo ocioso era um convite ao demônio, tinham muita força na jovem comunidade industrial. Como conseqüência disto, as jornadas de quatorze a dezesseis horas de labuta continuaram a ser costumeiras. As várias uniões sindicais, contudo, continuaram a postular menos horas de trabalho e como resultado de sua pressão bem sucedida, o Presidente Van Buren assinou a norma que fixava dez horas diárias de trabalho em portos governamentais da Marinha. Esta indicação, todavia, não foi rapidamente seguida pela indústria. Em algumas localidades, os operários da construção e outros artesãos habilitados só passaram a trabaIhar dez horas em 1845 e, com exceção destes trabalhadores habilitados e dos protegidos pela legislação laboral infantil, em certos Estados, as doze horas diárias continuaram a ser a regra até a guerra civil.

$O$ período que se seguiu à guerra civil foi marcado por especial interesse na redução das horas de trabalho. A depressão do pós-guerra produziu o desemprego, o qual foi adicionalmente agravado pelo retorno dos soldados a suas ocupações civis. O crescimento dos sindicatos nacionais durante este período proporcionou um meio através do qual os temores operários podiam ser articulados. Nos anos da década iniciada em 1880, o movimento pela redução de horas de trabalho recebeu forte ímpeto de patrocínio dos "Knights of Labor" (Cavaleiros do Tra-

9. BLOOM, Gordon F. e NORTHRUP, Herbert P. - Economics of Labor Relacions, $3^{\mathrm{a}}$. ed., Illinois, Homewood, 1958, página 524/525. 
balho), que no auge de seu poder tiveram êxito na obtenção de oito horas por dia de trabalho para mais de duzentos mil homens. Esta vitória, entretanto, foi apenas temporária. Com a extinção do grupo dos "Cavaleiros", as dez horas novamente se tornaram costumeiras, exceto para alguns trabalhadores estrategicamente situados, que podiam usar seu poder de negociação para obter menos horas. Em 1916, a “Big Four Railroad Brotherhoods", ameaçando uma suspensão de trabalho no país inteiro, obteve permissão legal através do Ato de Adamsom, para cumprir e assegurar uma jornada de oito horas para grupos de trabalhadores de estradas de ferro.

Convém lembrar que as conquistas norte-americanas para diminuir a jornada de trabalho foram acompanhadas por lutas no sentido de instituir o descanso semanal e obter a remuneração dos dias feriados. Este fenômeno também foi observado na Inglaterra e na França, embora o descanso semanal remunerado e os feriados só tenham sido objeto de regulamentação legal posterior, a despeito da forte influência religioda da comunidade protestante empenhada em cumprir e observar os preceitos bíblicos.

\section{NO BRASIL}

No Brasil, as normas reguladoras da jornada de trabalho começam a ser esboçadas, debilmente, com a vinda de trabalhadores europeus, no final do século XIX, para trabalhar na lavoura cafeeira da província de São Paulo. Até esta época, embora a Constituição de 1824, de cunho liberal, assegurasse o trabalho livre e extinguisse as corporações de ofício, as relações de trabalho dominantes em nosso pa ís eram de natureza escravagista, patriarcal ou corporativista, com jornadas de trabalho que, geralmente, iam de "sol a sol".

Somente no início do século $\mathrm{XX}$, com a crescente industrialização do Rio de Janeiro e de São Paulo, ocorreram as primeiras greves reivindicando melhores condições e menores jornadas de trabalho (1910 e 1917).

Francisco Weffort lembra que: "A classe operária do período pré-30 era duplamente marginal. No sentido político, porque o sistema oligárquico a excluia totalmente. Os operários praticamente não eram cidadãos. Além disso, eles se localizavam num setor econômico, o industrial, que estava em uma situação complementar ao centro egemônico, agrário-exportador". ${ }^{10}$

Nesse clima de completa marginalidade, as condições de trabalho dos operários brasileiros, em 1917, se assemelhavam e muito às dos operários ingleses e franceses da primeira metade do século $X I X$. No interior das fábricas, a disciplina era rigorosa, não só quanto aos horários e cadências, mas também com punições que resultavam em multas

10.WEFFORT, Francisco - Cadernos de Debates, Editora Brasiliense, São Paulo, 1976, n ${ }^{0} .1$, página 79 a 82. 
em que operários perdiam até um terço de seu salário, por cometerem erros insignificantes. Além disso, havia castigos corporais para os meninos aprendizes. No in ício do século, as classes dominantes brasileiras ignoravam as reivindicações dos trabalhadores e apesar das pressões internacionais, o Brasil não ratificou a Convenção $r^{\circ} 0.1$ de Versalles, ratificando, até 1930 apenas algumas Convenções quando então Getúlio Vargas para buscar apoio político nas classes trabalhadoras, começou a fomentar a organização dos sindicados e da Justiça Trabalhista, reformulando leis de inspiração nitidamente paternalista e até mesmo fascista que subsistem até hoje, regulando a duração da jornada de trabalho e as demais situações resultantes das relações trabalhistas.

A década de 1930 viu, portanto, surgir algo de mais concreto em nosso país no que respeita à duração do trabalho.

O Decreto 21186, de 22 de março de 1932 regulamentado pelo Decreto 22037, com certas alterações estabelecia em seu artigo 10. que: "A duração normal do trabalho efetivo dos estabelecimentos de qualquer natureza será de oito horas diárias, ou quarenta e oito horas semanais, de maneira que a cada período de seis dias de ocupação efetiva, corresponda um dia de descanso obrigatório".

No mesmo ano de 1932, publicou-se o Decreto 21364 o qual assegurava a jornada de oito horas para o trabalho industrial, com algumas hipóteses de prorrogação e exceções.

No ano seguinte, inúmeros decretos se seguiram dispondo sobre a jornada laboral em determinadas atividades, o que viria a ocorrer também no ano de 1934.

$\mathrm{Na}$ Constituição de 1934, algumas normas relativas ao trabalho e ao descanso foram incluídas, como por exemplo a do artigo 121:

“Artigo 121: A Lei promoverá o amparo da produção e estabelecerá as condições de trabalho, na cidade e nos campos, tendo em vista a proteção social do trabalhador e os interesses econômicos do pa ís".

b. 10.) A legislação do trabalho observará os seguintes preceitos, além de outros que colimem melhores às condições de trabalhador:

c. Trabalho diário não excedente de oito horas, reduz íveis, mas só prorrogáveis nos casos previstos pela lei;

d. Proibição de trabalho a menores de catorze anos; de trabalho noturno a menores de dezesseis anos; e em indústria insalubre, a menores de dezoito anos e a mulheres;

e. Repouso hebedomanário, de preferências aos domingos;

f. Férias anuais remuneradas ...".

Escreve o Prof. Aluysio Sampaio a respeito: “Em seu artigo 137, a Constituição de 1937 mandava a legislação ordinária do Trabalho obedecer a determinados preceitos constitucionais e, entre eles:

1) $O$ operário terá direito ao repouso semanal aos domingos $e$, nos limites das exigências técnicas da empresa, aos feriados civis e religiosos, de acordo com a tradição local (art. 137, d);

2) Dia de trabalho de oito horas, que poderá ser reduzido, é somente suscet ível de aumento nos casos previstos em lei (art. 137, i); 
$137, \mathrm{k}) ;^{\prime \prime} .11$

3) Proibição de trabalho noturno a menores de dezesseis anos (art.

Surgiu, ao mesmo tempo de vigência desta Constituição, o Decreto-Lei 5.542, de 10. de maio de 1943, que aprovou a Consolidação das Leis do Trabalho, em vigor, a 10 de novembro do mesmo ano. A C.L.T. regula a matéria relativa a jornada de trabalho em seu Título II, Cap ítulo II (Duração do Trabalho), Seção II, onde se acham disposições gerais referentes a este assunto, havendo ainda em outros artigos da Consolidação das Leis do Trabalho normas relativas ao trabalho e descanso dos menores, das mulheres e para determinadas profissões.

A Constituição de 18 de setembro de 1946 consagrou, também em n ível de direito constitucional, vários preceitos relativos a aspirações dos trabalhadores, o que podemos afirmar com base no artigo do Prof. Aluysio Sampaio.

A citada Constituição reconhece a duração diária do trabalho não excedente a oito horas, excetuados casos e condições previstos em lei. Continuou em vigor então, a Consolidação das Leis do Trabalho, que precedeu a aludida Constituição.

A Constituição de 1967 preserva os preceitos básicos de proteção ao trabalhador, assegurando a este a jornada laboral não excedente de oito horas, com intervalo para descanso, salvo casos excepcionalmente previstos (artigo 158, VI). Ficou explicitada, como lembra o Prof. Aluysio Sampaio, nesta Constituição a necessidade de intervalo para descanso.

A Emenda Constitucional no. 1, de 17 de outubro de 1929, reiterou os dispositivos da Constituição de 1967, no que diz respeito a trabalho e descanso.

Está regulamentada a matéria, atualmente, em nível de legislação ordinária, na Consolidação das Leis do Trabalho, e em outras leis que dispõe sobre categorias específicas.

\section{III - A CONTRIBUIC̣ĀO DO DIREITO INTERNACIONAL DO TRABALHO}

Nos meados do século XIX, o capital burguês europeu já havia se espalhado por todo o mundo e alterado, profundamente, a feição das sociedades européias e coloniais. O vigor da industrialização exigia, cada vez mais, novos mercados e novas guerras, exigindo esforços ilimitados das classes trabalhadoras, que em nada se beneficiavam de seu trabalho, tanto nas metrópoles quanto nas colônias, ou países dependentes. Tal situação fez com que se aprofundasse, no meio do movimento sindical, a consciência do papel desempenhado pelos operários nas sociedades burguesas industrializadas e a necessidade da união, ao n ível internacio-

11. SAMPAIO, Aluysio - Trabalho e Descanso, artigo publicado na Revista de Direito do Trabalho, set-out, ano $3,1978, n^{\circ} .15$, página 41 e 45 , Ed. Revista dos Tribunais. 
nal, de todos os trabalhadores, para obterem o reconhecimento de seus direitos e o espaço político no âmbito da organização estatal.

"A idéia da internacionalização das normas de proteção ao trabaIho não era nova e havia sido ensaiada várias vezes, por pensadores liberais como Robert Owen em sua obra "A New View of Society" e defendida por intelectuais como Luis Blanqui, mas a sua efetiva realização dar-se-ia quando os trabalhadores organizados passaram a representar um poder político no seio do Estado, e forçaram este Estado, inclusive no âmbito internacional, ao reconhecer seus direitos - idéia defendida pela "Assembléia Internacional dos Trabalhadores", criada em Londres, com o manifesto de Marx e Engels de 1864. adotando igualmente uma resolução pleiteando uma legislação social internacional, e defendendo a união do proletariado, com o fim de obter para si o poder político, a quem, mediante a socialização do Estado, deveria se entregar o poder econômico." 12

Para a internacionalização das normas trabalhistas também foi decisiva a posição adotada pela Igreja Católica que, com a edição da Encíclica Papal "Rerum Novarum" passou a pugnar pela necessidade de reforma e melhoria das condições de trabalho de toda a humanidade.

Apoiados por governos mais progressistas, filósofos e organismos como a Igreja, os operários continuaram a pressionar os governos ao nível nacional e internacional, tendo conseguido, ao findar o século $\mathrm{XIX}$, a jornada de trabalho de dez horas, para quase toda a europa e alguns países do Oriente e América.

Durante a Primeira Guerra Mundial (1914/18), a atuação dos sindicatos operários foi decisiva, resultando inclusive, na assinatura da paz em separado entre a Alemanha e a Rússia, através do Tratado de BrestLitosvisk e na instalação de um governo de orientação comunista na Rússia.

Terminada a Primeira Grande Guerra novos problemas surgiram entre trabalhadores e patrões, novas dificuldades não encontravam soluções pacíficas e o confronto foi inevitável. "Portanto, a guerra não ficou em calma, e quase que imediatamente após o seu término, a região de Clyde (Inglaterra) explodiu mais uma vez. A demissão dos operários das fábricas de munições parecia mergulhar Glasgow no desemprego. A solução proposta foi a drástica redução da semana de trabalho para qurenta horas semanais". ${ }^{13}$

De fato, uma das grandes vitórias conquistadas pelos operários ingleses, logo após o fim da guerra, foi conseguir a diminuição de cerca de seis horas e meia de trabalho por semana. Os líderes mais radicais pretendiam trinta horas semanais, não houve acordo, a violência generalizou-se, os tanques invadiram a cidade e os líderes foram processados por iniciar tumulto.

12. SUSSEKIND, Arnaldo - Obra citada, página 77.

13. LOYD, Trevor - Militância Sindical - Histórica do Século XX, nº 33, Ed. Abril, Rio, página 1003. 
Ao findar do século XIX, na Europa, de um modo geral, bem como nos pa íses americanos, com exceção dos EUA, a jornada de trabatho mais comum tinha a duração de dez horas e o regime das oito horas diárias só veio a ser conhecido, em quase todos os países do mundo, após a Primeira Guerra Mundial, quando em Versailles, foi assinada a Convenção no. 1 ratificada por trinta e dois países que previa duração de, no máximo, oito horas para o trabalho diário, e o limite semanal de quarenta e oito horas.

Com a assinatura da Convenção no. 1 e demais Convenções internacionais firmadas e ratificadas após 1919, o trabalho passou a ser regulado e protegido não só por normas elaboradas nos diversos países, mas também por normas de caráter internacional, adotadas pelos pa íses signatários que, ao ratificá-las admitiam-nas ao n ível interno em pé de igualdade com as leis elaboradas pelos seus respectivos sistemas legislativos nacionais. Deste modo, com a internacionalização das regras trabalhistas e com a criação da O.I.T, vários passos têm sido dados, no sentido da diminuição da jornada de trabalho, passos estes consubstanciados principalmente na Convenção no. 30 de 1930, que fixa a duração do trabalho no comércio e na indústria; a convenção n०. 47 de 1935, que fixou o limite semanal de 40 horas, seguidas das Convenções especiais e Recomendações como a no. 11.116, de 1962, que dispõe sobre a redução da jornada de trabalho.

\section{BIBLIOGRAFIA}

1. BLOOM, Gordon F. e NORTHRUP, Herbert P. - Economics of Labor Relations, $3^{\mathrm{a}}$. ed. Illinois, Homewood, 1958.

2. BRUN, André et GALLAND, Henri - Droit du Travail, Tome I, 2a. ed., Paris, Sirey, 1978.

3.CARPENTIER, J e CAZAMIAN, P. - El Trabajo Nocturno, Genebra, Publicações O.I.T, 1977.

4. CUVILliER, Rolande - Hacia la Reducción de la Duración del Trabajo?, Genebra, Publicações O.I.T., 1978.

5. LOY D, Trevor - Militância Sindical "in" História do Século XX, n . 33, Rio - Ed. Abril, 1973.

6. NAMIER, Lewis - 1848 - The Revolution of the Intellectuals, New York, Anchor Books, 1964.

7.SAMPAIO, Aluysio - Trabalho e Descanso - "in" Revista de Direito do Trabalho, RT, ano $3, n^{\circ} .15,1978$.

8.SUSSEKIND, Arnaldo - Direito Internacional do Trabalho, São Paulo, LTR, 1983.

9.WE FFORT, Francisco - Do Anarquismo ao Populismo, "in" Caderno de Debates 1, São Paulo, Ed. Brasiliense, 1976. 